\title{
Comparison of high-fat and high-carbohydrate foods in a meal or snack on short-term fat and energy intakes in obese women*
}

\author{
S. M. Green ${ }^{1}$, J. K. Wales ${ }^{2}$, C. L. Lawton ${ }^{1} \dagger$ and J. E. Blundell ${ }^{1}$ \\ ${ }^{1}$ School of Psychology and ${ }^{2}$ Department of Medicine, University of Leeds, Leeds, LS2 9JT, UK
}

(Received 5 July 1999 - Revised 22 November 1999 - Accepted 10 January 2000)

\begin{abstract}
The present study aimed to compare the action of high-fat and high-carbohydrate (CHO) foods on meal size (satiation) and post-meal satiety in obese women. A within-subjects design was used; each participant received all four nutritional challenges. Fifteen healthy obese women (age 21-56 years, BMI 35-48 kg/m²) participated; thirteen completed all four test days. On two test days, participants were exposed to a nutritional challenge comprising an ad libitum high-fat or high-CHO lunch. On the other two test days they were exposed to a challenge comprising an ad libitum sweet high-fat or high-CHO mid-afternoon snack. Energy and macronutrient intakes were measured at each eating episode. Visual analogue rating scales were completed periodically to record subjective feelings of appetite. When offered a high-CHO selection of foods at lunch and mid-afternoon participants consumed less energy than when offered a high-fat selection. However, post-meal satiety was similar. Total test-day energy intake was significantly higher when high-fat foods were consumed at lunch, but not as a snack. Consumption of high-fat foods at a lunch and snack increased the amount of fat consumed over the whole test day. In conclusion, energy intake of an eating episode was influenced by nutrient composition in this group of obese women. Consumption of high-fat foods at lunch or as a snack led to overconsumption relative to high-CHO foods. However, high-fat foods at meals may have greater potential to influence daily intake than at snacks, probably because meals are larger eating episodes and therefore give greater opportunity to overconsume.
\end{abstract}

High-fat: High-carbohydrate: Energy intake: Appetite control

There is considerable evidence that weight gain and obesity are associated with the amount of dietary fat consumed (Golay \& Bobbioni, 1997). The prevalence of obesity is greater amongst habitual high-fat consumers (Macdiarmid et al. 1996). Further, high-fat diets have been shown to promote weight gain (Lissner et al. 1987). The weight gain on highfat diets may be particularly marked in women who have a genetic predisposition to obesity (Heitmann et al. 1995). There is some evidence that formerly-obese women may have lower rates of fat oxidation than matched controls (Ranneries et al. 1998). The incidence of obesity in the UK is greater in women (particularly older middle-aged women) than in men (Prescott-Clarke \& Primatesta, 1997). This difference may well involve difficulties associated with food choice and the control of energy intake.

High-fat foods have the potential to generate a high energy intake by means of a process referred to as 'passive overconsumption' (Lawton et al. 1993). This nondeliberate consumption of energy derived from fat can lead to excessive intakes of fat in a single eating episode (meal or snack), and can produce a marked short-term (Lawton et al. 1993) positive energy balance. High-fat foods consumed at a meal have been shown to increase meal size in lean healthy males (Cotton et al. 1994; Green et al. 1994; King \& Blundell, 1995) and females (Green \& Blundell, 1996a), and obese women (Lawton et al. 1993). A subsequent compensatory underconsumption following a high-fat meal has been shown in some studies (Foltin et al. 1990), but not others (Stubbs et al. 1993).

The action of high-fat foods on appetite is almost certainly due to a combination of the high palatability (Warwick \& Schiffman, 1992) and energy density (Stubbs et al. 1996) of high-fat foods. These effects compromise appetite control through a weak action on satiation (Blundell et al. 1993). The effect of high-fat foods on subsequent satiety (inter-meal satiety) also appears weaker than that of high-carbohydrate $(\mathrm{CHO})$ foods, probably due to differences in post-ingestive processing. Indeed, it has

\footnotetext{
Abbreviations: $\mathrm{CHO}$, carbohydrate; VAS, visual analogue scales.

*Part of the data in this paper was presented at the 8th European Congress on Obesity, Dublin, Republic of Ireland, $18-21$ June 1997.

†Corresponding author: Dr C. L. Lawton, fax +44 113233 5749, email clarel@psychology.leeds.ac.uk
} 
been asserted that, 'joule-for-joule', fat may exert a weaker effect on satiety than carbohydrate (Rolls et al. 1994).

Many snack foods are characterised by a high content of both fat and sugar (Drewnowski, 1990). There is some evidence that obese female participants rate sweet high-fat foods as preferred food items (Drewnowski et al. 1992). In addition, analysing the data presented in the Dietary and Nutritional Survey of British Adults (Gregory et al. 1990) has shown that there is a marked consumption of sweet high-fat foods among obese (BMI $>30 \mathrm{~kg} / \mathrm{m}^{2}$ ) women but not men (Macdiarmid et al. 1998). Sweet high-fat snacks have been shown to lead to overconsumption when compared with other sensory-nutrient combinations in lean males (Green \& Blundell, 1996b). The effects of experimental manipulations of sweet high-fat or high- $\mathrm{CHO}$ foods on meal size has not been examined in the obese.

Lawton et al. (1993) showed that the energy intake of obese women at a test meal was increased when high-fat foods were consumed. Analysis of subsequent energy intake measured using food diaries suggested that energy intake was not reduced following the high-fat foods relative to the high-CHO foods. Conversely, some evidence suggests that obese individuals may compensate for a reduction in energy intake produced by a reduction in fat content of a meal (Fricker et al. 1995).

The present study included a manipulation of both meals and snacks because of opinions concerning the role of these different eating episodes in leading to a positive energy balance and weight gain. Although it is frequently claimed that snacking leads to weight gain, there is little objective evidence to support this claim (Mela \& Rogers, 1993; Green \& Burley, 1995). This study provided an opportunity to gather some evidence by comparing the impact of nutrient manipulations at a meal or snack on total test-day intake. Lawton et al. (1998) have shown that high-fat snack interventions do not lead to significantly increased daily energy intake but do markedly increase daily fat intake.

The present study examined the effect of highly-palatable high-fat and high-CHO foods, within the context of a normal meal pattern, on energy intake and motivation to eat of obese females. The effect of ad libitum consumption of (1) highfat and high-CHO foods at a lunch test meal on lunch and subsequent dinner meal size, and (2) sweet high-fat and high-CHO snack foods at a snack test meal on snack and subsequent dinner meal size were examined. The effects of consumption of high-fat and high-CHO foods at a lunch and snack on motivation to eat and total test-day energy and macronutrient intakes were also examined. The study provided an opportunity to examine issues concerning food and eating episodes in obese women, and to comment on other issues of theoretical importance.

\section{Methods \\ Study design}

The study used a within-subject design. Four nutritional challenges were introduced over a period of 4 weeks. The nutritional challenges involved ad libitum consumption of a high-fat and high-CHO lunch, and a high-fat or high-CHO snack. The challenges were presented in four different orders to counterbalance the order-of-treatment effect: high-fat lunch, high-fat snack, high-CHO lunch, highCHO snack (participants nos.1, 5, 9, 13); high-CHO lunch, high-CHO snack, high-fat lunch, high-fat snack (participants nos. 2, 6, 10, 14); high-fat lunch, high-CHO snack, high-CHO lunch, high-fat snack (participants nos. 3, 7, 11, 15); high-CHO lunch, high-fat snack, high-fat lunch, highCHO snack (participants nos. 4, 8, 12).

\section{Participants}

Fifteen healthy obese women were recruited from the outpatient Obesity Clinic of the local general hospital. Patients with stable weight $( \pm 2.5 \mathrm{~kg}$ ) during the 2 months before the start of the study were included.

The fifteen participants were aged 21-56 (mean 37, (SD 9)) years. Their mean weight at the beginning of the study was 104.3 (SD 14.8) $\mathrm{kg}$ and their mean BMI was 39.2 (SD $3.5) \mathrm{kg} / \mathrm{m}^{2}$. The thirteen participants who completed the study satisfactorily were aged 25-56 (mean 38 (SD 8)) years. Their mean pre-study weight was 104.2 (SD 15.0) kg and their mean BMI was 39.2 (SD 3.8) $\mathrm{kg} / \mathrm{m}^{2}$. The data obtained from two participants (nos. 6 and 9) were excluded from the analyses as they either failed to return the food box or consumed a meal not obtained from the food box on one of the test days.

Participants had no special dietary instruction for the duration of the study and were asked to maintain their normal dietary habits. Participants were not given any physical activity instruction but were simply asked to maintain their normal level of exercise throughout the study. Participants were requested not to drink alcohol to excess the day before each experimental day and on each experimental day.

\section{Test day procedure}

Participants were instructed to consume their customary breakfast on each test day, and to consume the same breakfast at the same time on each test day. Participants were asked not to eat or drink following breakfast, although they were permitted to consume one cup of tea or coffee during the course of the morning if this was their usual habit. One cup of tea or coffee was offered on the first test day with each test meal and, if taken, was given and consumed on subsequent test days as on the first test day. Caffeine intake was therefore kept constant. Unlimited drinking water was permitted throughout the experimental day and offered at each test meal. Participants were requested to arrive at the Unit $15 \mathrm{~min}$ before their test lunch.

Participants consumed all meals alone in a quiet small room cubicle. All cubicles were similar in appearance and size. Participants were requested not to read whilst consuming a meal.

Ad libitum lunch test days. Participants were presented with a lunch test meal which consisted of a range of highfat or high-CHO foods at 12.00 hours (in some cases lunch was given later to suit the participants' timetable, although, the time interval between meals remained constant). Participants were requested to eat from the foods until they felt comfortably full. The sensory quality of the meal 
was then rated. Participants were then requested to refrain from eating and drinking (except water) until their next test meal (dinner) $4 \mathrm{~h}$ later (one cup of tea or coffee during the afternoon was permitted if this was their normal habit). Participants were requested to consume exactly the same drink on each of the test days. Participants either remained in the Unit or left and returned in time for the next test meal. A further ad libitum test meal (dinner) was presented $4 \mathrm{~h}$ after the lunch test meal. This meal consisted of a range of foods of medium palatability. Participants were requested to eat from these foods until they felt comfortably full, and to complete sensory ratings following the meal. Following this meal participants left the unit with a food box to eat from for the rest of the evening, and a record sheet to record what and when they ate from the box. Participants completed visual analogue scales (VAS) to measure motivation to eat at regular intervals throughout the experimental day.

Ad libitum snack test days. Participants were presented with a fixed-energy lunch meal of medium palatability at 12.00 hours (in some cases lunch was given later to suit the participants' timetable, although the time interval between meals remained constant). Participants were requested to consume all the meal, and to complete sensory ratings. Participants were then requested to refrain from eating and drinking (except water) until the test snack $2 \mathrm{~h}$ later. An $a d$ libitum selection of snacks were presented $2 \mathrm{~h}$ following the lunch meal. These snacks consisted of a range of sweet foods high in $\mathrm{CHO}$ or high in fat. Participants were requested to eat from these foods until they felt comfortably full, and to complete sensory ratings as before. A further $a d$ libitum test meal (dinner) was presented $2 \mathrm{~h}$ following the test snack. The test-meal dinner and procedure following the test dinner were the same as on the days when the test lunches were consumed.

\section{Test meals}

All foods presented were those encountered in real eating situations. All were palatable, not unusual and were obtainable from the supermarket. The protein levels were kept low and constant between the nutritional challenges. Protein content of a meal has been shown to increase satiety (Barkeling et al. 1990). Dietary fibre has been shown to influence appetite (Blundell \& Burley, 1987). Most of the foods selected for the test snack and lunch were considered to contain only small amounts of dietary fibre. Where foods were considered higher in fibre (coleslaw, popcorn), they were offered in both the high-fat and high$\mathrm{CHO}$ conditions. The glycaemic index of the foods was not considered; foods were selected only to meet specific criteria concerning macronutrient content. Foods were given at customary meal times. This procedure allowed experimental manipulations within the context of natural meal patterns.

Palatability is thought to be the most consistent variable influencing the amount eaten (Spitzer \& Rodin, 1981). The palatability of the ranges of foods used in the selections was therefore controlled. Before the start of the study each participant completed a preference form to ensure that the foods were acceptable. Acceptability was assessed by using a 9-point scale, with 9 being rated as 'like extremely'. If participants rated items $\geq 5$, it was concluded that they did not dislike the food. If a food item was rated $<5$, then a 'liked' food item was substituted. Any substituted foods were similar in texture and nutritional content. All food items were therefore rated as $\geq 5$, except for salad and condiments in the ad libitum test dinner.

Ad libitum test lunch. Two types of test lunch were used: high-fat low-CHO, and high-CHO low-fat, classified according to the percentage of energy obtained from fat and CHO. Each ad libitum lunch consisted of seven food items. The seven high-fat food items in the high-fat lunch derived more than $51 \%$ total energy from fat and less than $42 \%$ from $\mathrm{CHO}$. Six of the high-CHO food items in the high$\mathrm{CHO}$ lunch derived more than $54 \%$ total energy from $\mathrm{CHO}$ and less than $30 \%$ from fat. One food item (coleslaw) derived $48 \%$ energy from fat and $41 \%$ energy from CHO. However, as the fat content was $3.2 \mathrm{~g} / 100 \mathrm{~g}$ coleslaw, this item was considered to be a low-fat food. Table 1 lists the food items, nutritional information and quantity offered. An excess of food was offered, and no participant ate all the foods on any one occasion.

Fixed test lunch. This meal was of medium palatability, consisting of hot meat-and-potato pie, green peas, two sweet biscuits and a glass of orange juice. The energy content of the meal was $2.08 \mathrm{MJ}$ (497 kcals); $16 \%$ energy from protein, $51 \%$ energy from $\mathrm{CHO}$ and $33 \%$ energy from fat. Participants were requested to consume all the meal. Lasagne was offered as an alternative if participants expressed a dislike for meat-and-potato pie before the start of the study, and alternative vegetables were offered if green peas were disliked. The macronutrient and energy contents of the substituted foods were very similar to the foods they replaced.

Ad libitum test snack. The ad libitum sweet snacks used were high-fat low-CHO and high-CHO low-fat, classified according to the percentage of energy obtained from fat and CHO. Each snack consisted of five food items. The five high-fat food items in the high-fat snack derived $>52 \%$ total energy from fat and $<41 \%$ energy from $\mathrm{CHO}$. The five high-CHO food items in the high-CHO snack derived $>60 \%$ of total energy from $\mathrm{CHO}$ and $<33 \%$ from fat. Table 2 lists the food items, nutritional information and quantity offered. An excess of food was offered, and no participant ate all the foods on any one occasion. The dessert was served chilled, and the items were presented on one tray.

Ad libitum test dinner. At the ad libitum evening meal participants were provided with a range of foods of medium palatability from which they could select the type and amount they wished to consume. The foods offered are often consumed as part of a meal and included bread, margarine, sliced cold meat, cheese, salad items, condiments, potato crisps, fruit yoghurt and fruit.

Food for the rest of the day. Participants were provided with a range of food items commonly consumed as a snack in the evening, including bread, margarine, jam, cheese, milk-based pudding (e.g. fruit yoghurt or chocolate dessert), chocolate biscuits and potato crisps. The food items did not require refrigeration and were presented in a sealed plastic box. An excess of food was offered, and no 
Table 1. Quantity, energy content and macronutrient composition of food items offered in the high-carbohydrate (CHO), low-fat and high-fat low$\mathrm{CHO}$ ad libitum test lunches

\begin{tabular}{|c|c|c|c|c|c|c|c|c|c|}
\hline & \multirow[b]{2}{*}{ Quantity (g) } & \multicolumn{2}{|c|}{ Energy } & \multicolumn{2}{|c|}{ Protein } & \multicolumn{2}{|c|}{$\mathrm{CHO}$} & \multicolumn{2}{|c|}{ Fat } \\
\hline & & $\mathrm{MJ} / 100 \mathrm{~g}$ & $\mathrm{kcal} / 100 \mathrm{~g}$ & $\mathrm{~g} / 100 \mathrm{~g}$ & $\%$ energy & $\mathrm{g} / 100 \mathrm{~g}$ & $\%$ energy & $\mathrm{g} / 100 \mathrm{~g}$ & \% energy \\
\hline \multicolumn{10}{|l|}{ High-CHO lunch } \\
\hline 1. Tuna mayonnaise sandwiches & Eight quarters & 0.71 & 170 & $10 \cdot 6$ & 25 & 24.9 & 55 & $3 \cdot 8$ & 20 \\
\hline 2. Coleslaw & 200 & 0.25 & 60 & $1 \cdot 8$ & 12 & 6.5 & 41 & $3 \cdot 2$ & 48 \\
\hline 3. Breadsticks & 65 & 1.60 & 383 & $12 \cdot 0$ & 13 & $72 \cdot 0$ & 70 & $7 \cdot 2$ & 17 \\
\hline 4. Crispy potato snacks (French Fries) & 36 & 1.73 & 415 & 5.4 & 5 & $72 \cdot 9$ & 66 & $13 \cdot 3$ & 29 \\
\hline 5. Ham and mushroom pizza & 330 & 0.89 & 212 & $9 \cdot 6$ & 18 & 32.4 & 57 & $5 \cdot 8$ & 25 \\
\hline Or cheese and tomato pizza & 330 & 0.94 & 225 & 8.9 & 16 & 33.0 & 55 & $7 \cdot 3$ & 29 \\
\hline 6. Jelly confectionery & 175 & $1 \cdot 32$ & 315 & $5 \cdot 2$ & 7 & $78 \cdot 4$ & 93 & 0.0 & 0 \\
\hline 7. Low-fat strawberry yoghurt & 300 & 0.36 & 87 & 4.7 & 22 & $14 \cdot 2$ & 61 & $1 \cdot 7$ & 18 \\
\hline \multicolumn{10}{|l|}{ High-fat lunch } \\
\hline 1. Tuna mayonnaise sandwiches & Eight quarters & 1.18 & 282 & $11 \cdot 1$ & 16 & $16 \cdot 4$ & 22 & $19 \cdot 6$ & 63 \\
\hline 2. Coleslaw & 200 & 1.38 & 331 & 1.1 & 1 & $4 \cdot 2$ & 5 & 34.5 & 94 \\
\hline 3. Maize snacks (cheese puffs) & 50 & $2 \cdot 22$ & 531 & $9 \cdot 1$ & 7 & $50 \cdot 9$ & 36 & 33.7 & 57 \\
\hline 4. Crackers with cheese filling (Ritz) & 90 & $2 \cdot 07$ & 496 & $11 \cdot 6$ & 9 & $50 \cdot 5$ & 38 & $28 \cdot 9$ & 52 \\
\hline 5. Meat-filled pastry (sausage rolls) & 160 & 1.35 & 323 & 7.5 & 9 & 24.5 & 28 & $22 \cdot 4$ & 62 \\
\hline Or cheese and onion flan & 365 & $1 \cdot 12$ & 267 & $8 \cdot 8$ & 13 & $22 \cdot 1$ & 31 & $16 \cdot 5$ & 56 \\
\hline 6. Vanilla-flavour biscuits (Vienna) & Eight biscuits & $2 \cdot 29$ & 548 & 4.4 & 3 & $60 \cdot 0$ & 41 & 33.9 & 56 \\
\hline 7. Strawberry cream and yoghurt dessert & 300 & 0.71 & 169 & 2.5 & 6 & $16 \cdot 5$ & 37 & $10 \cdot 8$ & 58 \\
\hline
\end{tabular}

Table 2. Quantity, energy and macronutrient composition of food items offered in the sweet high-carbohydrate (CHO) and sweet high-fat ad libitum test snack meals ${ }^{\star}$

\begin{tabular}{|c|c|c|c|c|c|c|c|c|c|}
\hline & \multirow[b]{2}{*}{ Quantity (g) } & \multicolumn{2}{|c|}{ Energy } & \multicolumn{2}{|c|}{ Protein } & \multicolumn{2}{|c|}{$\mathrm{CHO}$} & \multicolumn{2}{|c|}{ Fat } \\
\hline & & $\mathrm{MJ} / 100 \mathrm{~g}$ & $\mathrm{kcal} / 100 \mathrm{~g}$ & $\mathrm{~g} / 100 \mathrm{~g}$ & $\%$ energy & $\mathrm{g} / 100 \mathrm{~g}$ & $\%$ energy & $\mathrm{g} / 100 \mathrm{~g}$ & \% energy \\
\hline \multicolumn{10}{|l|}{ Sweet high-CHO snack } \\
\hline 1. Banana flavoured milk-based dessert & 300 & 0.41 & 98 & $2 \cdot 8$ & 11 & $15 \cdot 9$ & 61 & $3 \cdot 0$ & 28 \\
\hline $\begin{array}{l}\text { 2. Fruit-preserve-filled sponge cake } \\
\text { (Swiss roll) }\end{array}$ & 170 & $1 \cdot 18$ & 283 & 4.9 & 7 & $66 \cdot 2$ & 88 & $1 \cdot 7$ & 5 \\
\hline 3. Chocolate-and orange-topped biscuits & Eight biscuits & 1.52 & 364 & 4.4 & 5 & $72 \cdot 8$ & 75 & $8 \cdot 1$ & 20 \\
\hline 4. Toffee popcorn & 75 & 1.64 & 393 & $2 \cdot 6$ & 3 & $83 \cdot 1$ & 79 & 7.9 & 18 \\
\hline 5. White-chocolate cereal bars & Four bars & 1.67 & 400 & $6 \cdot 5$ & 7 & $66 \cdot 0$ & 62 & $14 \cdot 0$ & 32 \\
\hline \multicolumn{10}{|l|}{ Sweet high-fat snack } \\
\hline $\begin{array}{l}\text { 1. Gooseberry cream and yoghurt } \\
\text { dessert }\end{array}$ & 300 & 0.66 & 159 & $2 \cdot 3$ & 6 & $13 \cdot 3$ & 31 & $11 \cdot 1$ & 63 \\
\hline 2. Roasted-nut cereal bars & Four bars & $2 \cdot 10$ & 503 & $10 \cdot 0$ & 8 & $52 \cdot 8$ & 39 & 29.4 & 53 \\
\hline $\begin{array}{l}\text { 3. Croissants with fruit preserve } \\
\text { and butter }\end{array}$ & Three croissants & 1.73 & 414 & $5 \cdot 9$ & 6 & $42 \cdot 9$ & 39 & $25 \cdot 5$ & 55 \\
\hline 4. Caramel popcorn & 100 & $2 \cdot 22$ & 531 & $2 \cdot 6$ & 2 & $54 \cdot 2$ & 38 & $35 \cdot 3$ & 60 \\
\hline $\begin{array}{l}\text { 5. Chocolate-coated chocolate } \\
\text { sponge cake }\end{array}$ & Three cakes & $2 \cdot 01$ & 480 & $5 \cdot 5$ & 5 & $51 \cdot 7$ & 40 & 29.4 & 55 \\
\hline
\end{tabular}

* Acceptability of individual food items was assessed before the start of the study. Substitute food items of similar texture and nutritional content were offered when necessary. Substitute food items for the sweet high-CHO snack test meal were chocolate-flavoured milk-based dessert (one participant) and chocolate sponge and fondant cakes (six participants). Substitute food items for the sweet high-fat snack test meal were chocolate dessert (one participant) and vanilla-flavoured biscuits (two participants).

participant ate all the foods on any occasion. Intake of beverages was not restricted and participants were asked to record in detail drinks consumed.

\section{Motivational ratings}

Participants were requested to complete VAS to measure subjective hunger and other sensations associated with the willingness to eat. The VAS were $100 \mathrm{~mm}$ lines anchored by descriptors at each end. Participants were asked to mark, with a single vertical line, at a point where the length of the line matched the subjective sensation. VAS were completed immediately before and after each meal, and half-hourly between the test lunch and test dinner.

VAS were also completed after each test meal to assess the sensory qualities of the foods following consumption. Participants were asked how tasty, salty, filling, pleasant, bland and satisfying they found the meal or snack using a $100 \mathrm{~mm}$ linear VAS. In addition, participants were asked to rate how sweet they found the snacks.

\section{Statistical analysis}

Energy and macronutrient content of the test meals and food diaries was measured using manufacturers' data and a 
computerised nutritional database (Comp-eat, version 4; Nutrition Systems, London, UK) based on the UK food composition tables (Holland et al. 1991). Portion sizes for estimation of intake from the food diaries were calculated using standard food portion sizes (Ministry of Agriculture, Fisheries and Food, 1993). The energy conversion factors used were $15.7 \mathrm{~kJ} / \mathrm{g}(3.75 \mathrm{kcal} / \mathrm{g})$ for $\mathrm{CHO}, 37.7 \mathrm{~kJ} / \mathrm{g}$ $(9 \mathrm{kcal} / \mathrm{g})$ for fat and $16.7 \mathrm{~kJ} / \mathrm{g}(4 \mathrm{kcal} / \mathrm{g})$ for protein.

ANOVA was used to analyse the VAS post high-CHO or high-fat manipulation with time of rating and lunch or snack type as within-subjects variables. Student's paired $t$ tests were used to analyse the differences in energy and macronutrient intakes between the challenges, and the sensory ratings of the test meals.

Total test-day energy and macronutrient intakes were calculated as the sum of all food and drink consumed throughout the day; the fixed breakfast, beverages, lunch meal, snack meal (when consumed), dinner meal and snack box intake. As two participants failed to return a record of intake from the evening snack box on one test day, analyses included data for thirteen participants.

Two participants consumed alcoholic drinks during the evening. One participant consumed no more than two units of alcohol (wine and spirits) on each test day except one. The other participant consumed $23 \mathrm{~g}$ whisky and $1759 \mathrm{~g}$ and $251 \mathrm{~g}$ lager on three test days respectively. The data were analysed excluding these two participants but no differences were seen in the probability levels for the snack box energy intake following the high-fat and high-CHO lunches $(t 0 \cdot 98$, df 10, NS) and snacks $(t-0 \cdot 18$, df 10, NS), or for the energy intake over the total test day following the high-fat and high-CHO lunch $(t-3.22$, df $10, P<0.01)$ and snack $(t-1 \cdot 16$, df 10, NS) challenges. Thus, rest of day and total test day intakes include energy and macronutrients obtained from alcoholic drinks.

The statistical software packages used were Statistical Analysis Systems version 6.10 (SAS Institute, Cary, NC, USA), Statistical Package for Social Scientists version 6.1 (SPSS Inc., Chicago, IL, USA) and Minitab version 5 (Minitab Inc., State College, PA, USA).

The data from participants nos. 6 and 9 were not included in the analyses. Thus, four participants were allocated to the high-fat lunch, high-CHO snack, high-CHO lunch, high-fat snack order of treatment and three participants to the other orders of treatment. No significant differences were seen between the energy intakes of the first and second lunch $(t-0 \cdot 32$, df 12 , NS) and snack $(t$ $0 \cdot 21$, df 12 , NS) presented.

\section{Ethical considerations}

The study was approved by the Research Ethics Committee of the local NHS Trust, as part of a wider study. Information about the study was provided and informed consent obtained from all participants. The participants were not informed as to the exact nature of the dietary manipulation, but were fully informed when they had completed the study.

\section{Results \\ Lunch test days}

Energy and macronutrient intakes. Energy and macronutrient intakes for the ad libitum test lunch, ad libitum test diner, rest of the day (snack box) and total test day are shown in Table 3. Energy intake was greater when the high-fat lunch was consumed than when the high-CHO lunch was consumed $(t-5.93$, df $12, P<0.001)$. Energy intakes following the high-fat and high-CHO lunches did not differ at the test dinner $(t 0 \cdot 29$, df 12 , NS) or from the snack box ( $t 0 \cdot 46$, df 12, NS). Total day energy intake was less following the high-CHO lunch than following the highfat lunch $(t-3 \cdot 76$, df 12, $P<0.01)$.

Considering macronutrient intake, there was no significant difference between the protein intake at the high-CHO lunch and the high-fat lunch $(t 1 \cdot 17$, df 12 , NS).

CHO intake was $26 \%$ total energy (72 g) at the high-fat lunch and $60 \%$ total energy (101 g) at the high-CHO lunch. CHO intake $(\mathrm{g})$ was significantly higher at the high$\mathrm{CHO}$ lunch than at the high-fat lunch ( $t$ 3.66, df 12 , $P<0.01$ ), as would be expected. Total test day $\mathrm{CHO}$ intake (g) was higher when the high-CHO lunch was consumed $(t 2 \cdot 38$, df $12, P<0 \cdot 05)$. The percentage energy obtained from $\mathrm{CHO}$ on the test day when the high-CHO lunch was consumed was $47 \%$ compared with $35 \%$ when the high-fat lunch was consumed.

Fat intake was $64 \%$ total energy at the high-fat lunch $(75 \mathrm{~g})$ and $22 \%$ total energy (16 g) at the high-CHO lunch. Fat intake (g) was significantly lower at the high-CHO lunch than at the high-fat lunch $(t-11 \cdot 14$, df 12, $P<0.001$ ), as would be expected. Further, total test day fat intake (g) was lower with the high-CHO lunch than the high-fat lunch $(t-8.06$, df $12, P<0.001)$. The percentage energy obtained from fat on the test day when the highCHO lunch was consumed was $35 \%$ compared with $51 \%$ when the high-fat lunch was consumed.

There was a large difference between mean weight consumed at the high-fat (337 (SD 75) g) and the high-CHO meal (397 (SD 68) g). Intake (g) was approximately $20 \%$ greater with the high-CHO lunch than with the high-fat lunch $(t 3 \cdot 84$, df 12, $P<0 \cdot 01)$.

Sensory ratings. There were no significant differences in the recorded palatability of the high-fat and high- $\mathrm{CHO}$ lunches on the descriptors of tasty $(t 1.07$, df 12 , NS), salty $(t 1 \cdot 33$, df 12 , NS), filling ( $t 1 \cdot 85$, df 12 , NS), pleasant $(t 1.08$, df 12 , NS), bland $(t-0 \cdot 30$, df 12 , NS) and satisfying $(t 0 \cdot 18$, df 12 , NS). The lunch meals were rated as highly palatable by the participants. The mean rating on the $100 \mathrm{~mm}$ scale for the descriptor tasty was 78 (SD 11) mm for the high-CHO lunch and 70 (SD 28) $\mathrm{mm}$ for the high-fat lunch. The mean rating on the $100 \mathrm{~mm}$ scale for the descriptor pleasant was 79 (SD 18) $\mathrm{mm}$ for the high-CHO lunch and 71 (SD 24) mm for the high-fat lunch.

Motivation to eat. Fig. 1 shows the temporal profile of hunger ratings from immediately before the start of the lunch (pre-lunch) to immediately following the test dinner. Hunger levels can be seen to fall after meals and then rise until the next meal. Hunger levels following the two lunch types appear very similar. Two-way repeated measures ANOVA of hunger ratings from post-lunch to pre-dinner 
Table 3. Dietary energy and macronutrient intakes of thirteen obese women at a high-carbohydrate (CHO) ad libitum test lunch, a high-fat ad libitum test lunch, a subsequent ad libitum test dinner, over the rest of the day and for the total test day*

(Mean values and standard deviations)

\begin{tabular}{|c|c|c|c|c|c|c|}
\hline & \multicolumn{2}{|c|}{ High-CHO-lunch test day } & \multicolumn{2}{|c|}{ High-fat-lunch test day } & \multicolumn{2}{|c|}{$\begin{array}{c}\text { Statistical significance of difference } \\
\text { between challenges }\end{array}$} \\
\hline & Mean & SD & Mean & SD & $t(\mathrm{df} 12)$ & $P<$ \\
\hline $\begin{array}{l}\text { Ad libitum test lunch } \\
\text { Energy: } \mathrm{MJ}\end{array}$ & $2 \cdot 63$ & 0.70 & 4.39 & $1 \cdot 25$ & -5.93 & 0.001 \\
\hline Fat (q) & 628 & 167 & 1051 & 298 & & \\
\hline Fat $(\mathrm{g})$ & $15 \cdot 6$ & 3.8 & $75 \cdot 2$ & $20 \cdot 8$ & -11.14 & 0.001 \\
\hline $\mathrm{CHO}(\mathrm{g})$ & $101 \cdot 0$ & $32 \cdot 3$ & $72 \cdot 4$ & $31 \cdot 0$ & 3.66 & 0.01 \\
\hline Protein $(\mathrm{g})$ & $27 \cdot 2$ & $6 \cdot 1$ & $25 \cdot 5$ & $6 \cdot 2$ & 1.17 & NS \\
\hline \multicolumn{7}{|l|}{ Ad libitum test dinner } \\
\hline $\mathrm{kcal}$ & 595 & 237 & 582 & 251 & & \\
\hline Fat $(\mathrm{g})$ & 30.4 & 13.7 & $27 \cdot 7$ & $14 \cdot 6$ & 1.04 & NS \\
\hline $\mathrm{CHO}(\mathrm{g})$ & $53 \cdot 6$ & $26 \cdot 1$ & $58 \cdot 3$ & $26 \cdot 5$ & -0.96 & NS \\
\hline Protein (g) & $29 \cdot 9$ & $10 \cdot 3$ & $28 \cdot 4$ & 11.5 & 1.00 & NS \\
\hline \multicolumn{7}{|l|}{ Rest of day $\dagger$} \\
\hline Energy: MJ & $1 \cdot 70$ & 127 & 1.56 & 1.23 & 0.46 & NS \\
\hline kcal & 406 & 305 & 374 & 295 & & \\
\hline Fat $(\mathrm{g})$ & $18 \cdot 8$ & 14.4 & 15.5 & $13 \cdot 9$ & 0.80 & NS \\
\hline $\mathrm{CHO}(\mathrm{g})$ & $45 \cdot 6$ & $37 \cdot 0$ & $45 \cdot 9$ & $36 \cdot 1$ & -0.03 & NS \\
\hline Protein $(\mathrm{g})$ & $12 \cdot 3$ & $12 \cdot 2$ & $10 \cdot 8$ & $9 \cdot 2$ & 0.67 & NS \\
\hline \multicolumn{7}{|l|}{ Total test day $\ddagger$} \\
\hline Energy: MJ & 7.67 & $2 \cdot 27$ & $9 \cdot 16$ & $2 \cdot 76$ & $-3 \cdot 76$ & 0.01 \\
\hline kcal & 1835 & 543 & 2192 & 661 & & \\
\hline Fat $(\mathrm{g})$ & $72 \cdot 3$ & $23 \cdot 7$ & $124 \cdot 3$ & $37 \cdot 0$ & -8.06 & 0.001 \\
\hline $\mathrm{CHO}(\mathrm{g})$ & $230 \cdot 3$ & 78.7 & $205 \cdot 3$ & $84 \cdot 6$ & $2 \cdot 38$ & 0.05 \\
\hline Protein $(\mathrm{g})$ & $75 \cdot 8$ & $18 \cdot 0$ & $71 \cdot 0$ & $19 \cdot 1$ & 1.92 & NS \\
\hline
\end{tabular}

* For details of subjects, procedures and test lunches, see pp. 522-525 and Table 1 respectively.

$\dagger$ Calculated from food items consumed from the snack box plus beverages consumed in the evening.

¥ Calculated from the fixed breakfast, ad libitum test lunch, ad libitum test dinner, snack box and beverages consumed throughout the day.

showed a main effect of time $(F(5,60) 15.95, P<0.001)$, but no main effect of lunch type $(F(1,12) 0 \cdot 08, \mathrm{NS})$ or lunch $\times$ time interaction effect $(F(5,60) 1 \cdot 42, \mathrm{NS})$.

\section{Snack test days}

Energy and macronutrient intakes. The energy intake from the snack can be seen in Table 4. Energy intake was higher with the high-fat snack than with the high-CHO snack $(t-3.93$, df $12, P<0.01)$.

Energy intakes for the test dinner, the rest of the day (snack box and beverages) and the total test day are shown in Table 4. There were no significant differences between the energy intakes of the test dinner $(t 0.71$, df 12 , NS) or the rest of the day $(t-0 \cdot 42$, df 12 , NS). Examination of Table 4 shows that energy intake over the total test day was higher when the high-fat snacks were consumed. However, there were no significant differences between the two challenges $(t-1.70$, df 12 , NS).

Mean intakes of protein were 8 (SD 4) g and 10 (SD 4) g for the high-CHO and high-fat snacks respectively; this difference was significant $(t-2.32$, df $12, P<0.05)$. Protein intakes from the snacks were, however, similar in terms of percentage energy intake: 7 high-CHO snack, and 6 high-fat snack. The increase in protein intake with the high-fat snack, therefore, appeared to reflect the increased energy intake.

As expected, fat intake (g) at the test snack was significantly higher with the high-fat snack (42 g) than with the high-CHO snack $(11 \mathrm{~g} ; t-6.40$, df 12 , $P<0.001)$. CHO intake $(\mathrm{g})$, however, was not significantly different between the two challenges for either the test snack $(t 1 \cdot 65$, df 12 , NS) or total test day $(t 1.06$, df 12 , NS). Total test day fat intake (g) was lower with the highCHO snack than with high-fat snack $(t-4 \cdot 06$, df 12 , $P<0.01$ ). The percentage energy obtained from fat for the total test day when the high-CHO snack was consumed was $35 \%$ compared with $44 \%$ when the high-fat snack was consumed.

Intake (g) of the high-CHO snack was 191 (SD 127) $\mathrm{g}$ and of the high-fat snack was 167 (SD 90) g, but this difference was not significant ( $t$ 0.78, df 12, NS).

Sensory ratings. There were no significant differences in the recorded palatability of the high-fat and high-CHO snacks on the descriptors of taste $(t 0 \cdot 35$, df $12, \mathrm{NS})$, salty $(t-1 \cdot 10$, df 12 , NS), filling $(t 0 \cdot 17$, df 12 , NS), pleasant $(t-0.57$, df 12 , NS), bland ( $t 1.09$, df 12 , NS), sweet $(t 1 \cdot 21, \mathrm{df} 12, \mathrm{NS})$ and satisfying $(t-0 \cdot 37$, df 12 , NS $)$. The snack meals were rated as highly palatable by the participants. The mean rating on the $100 \mathrm{~mm}$ scale for the descriptor tasty was 84 (SD 13) $\mathrm{mm}$ for the high-CHO snack and 82 (SD 13) $\mathrm{mm}$ for the high-fat snack. The mean raging on the $100 \mathrm{~mm}$ scale for the descriptor pleasant was 85 (SD 16) $\mathrm{mm}$ for the high-CHO snack and 86 (SD 13) $\mathrm{mm}$ for the high-fat snack.

Motivation to eat. Fig. 2 shows the temporal profile of 


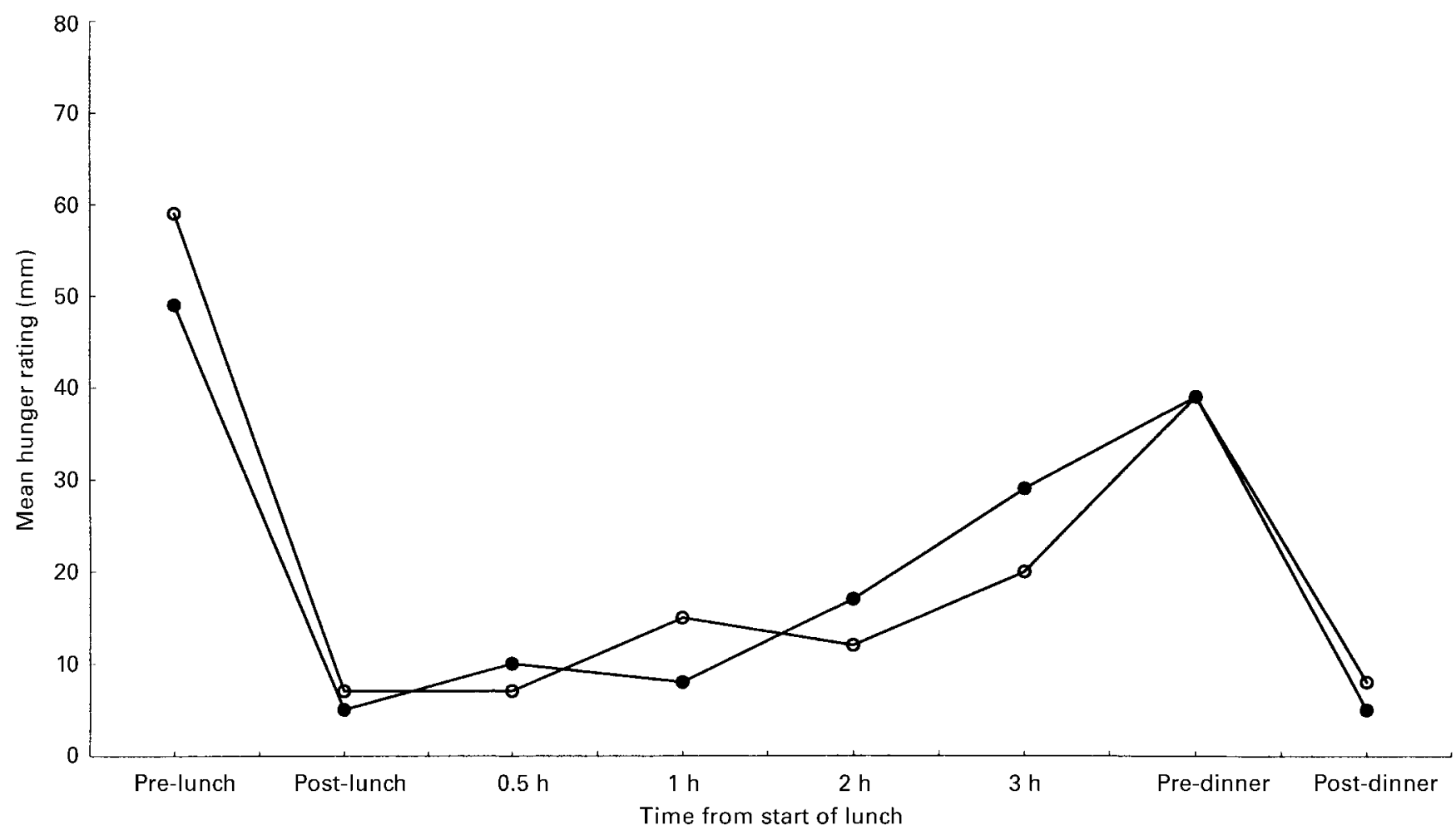

Fig. 1. Temporal profile of rated hunger immediately before (pre-lunch) until immediately following ad libitum consumption of a high-fat ( $\bullet$ ) or highcarbohydrate $(O)$ test lunch in obese women. Subjective hunger ratings were measured on visual analogue scales with $100 \mathrm{~mm}$ lines anchored by descriptors at each end. For details of procedures and test lunches, see pp. 522-525 and Table 1.

Table 4. Dietary energy and macronutrient intakes of thirteen obese women at a high-carbohydrate (CHO) ad libitum test snack, a high-fat ad libitum test snack, a subsequent ad libitum test dinner, over the rest of the day and for the total test day*

(Mean values and standard deviations)

\begin{tabular}{|c|c|c|c|c|c|c|}
\hline & \multicolumn{2}{|c|}{ High-CHO snack test day } & \multicolumn{2}{|c|}{ High-fat snack test day } & \multicolumn{2}{|c|}{$\begin{array}{c}\text { Statistical significance of difference } \\
\text { between challenges }\end{array}$} \\
\hline & Mean & SD & Mean & SD & $t(\mathrm{df} 12)$ & $P<$ \\
\hline $\begin{array}{l}\text { Ad libitum test snack } \\
\text { Energy: MJ } \\
\quad \text { kcal } \\
\text { Fat }(\mathrm{g}) \\
\mathrm{CHO}(\mathrm{g}) \\
\text { Protein }(\mathrm{g})\end{array}$ & $\begin{array}{c}1.91 \\
458 \\
11.3 \\
86.5 \\
7.9\end{array}$ & $\begin{array}{c}1 \cdot 05 \\
252 \\
5 \cdot 9 \\
50 \cdot 8 \\
4 \cdot 1\end{array}$ & $\begin{array}{l}2 \cdot 89 \\
691 \\
42 \cdot 3 \\
71 \cdot 5 \\
10 \cdot 3\end{array}$ & $\begin{array}{c}1 \cdot 39 \\
333 \\
20 \cdot 8 \\
34 \cdot 8 \\
4.3\end{array}$ & $\begin{array}{r}-3.93 \\
-6.40 \\
1.65 \\
-2.32\end{array}$ & $\begin{array}{l}0.01 \\
0.001 \\
\text { NS } \\
0.05\end{array}$ \\
\hline $\begin{array}{l}\text { Ad libitum test dinner } \\
\text { Energy: } \mathrm{MJ} \\
\quad \mathrm{kcal} \\
\text { Fat }(\mathrm{g}) \\
\mathrm{CHO}(\mathrm{g}) \\
\text { Protein }(\mathrm{g})\end{array}$ & $\begin{array}{c}2 \cdot 19 \\
524 \\
27 \cdot 4 \\
46 \cdot 6 \\
25 \cdot 4\end{array}$ & $\begin{array}{c}0.72 \\
172 \\
11 \cdot 3 \\
16 \cdot 7 \\
9.5\end{array}$ & $\begin{array}{l}2 \cdot 03 \\
486 \\
26 \cdot 0 \\
40 \cdot 4 \\
25 \cdot 1\end{array}$ & $\begin{array}{c}0.74 \\
177 \\
12 \cdot 6 \\
20.6 \\
6.5\end{array}$ & $\begin{array}{l}0.71 \\
\\
0.48 \\
1.09 \\
0.13\end{array}$ & $\begin{array}{l}\text { NS } \\
\text { NS } \\
\text { NS } \\
\text { NS }\end{array}$ \\
\hline $\begin{array}{l}\text { Rest of day† } \\
\text { Energy: MJ } \\
\quad \text { kcal } \\
\text { Fat }(\mathrm{g}) \\
\mathrm{CHO}(\mathrm{g}) \\
\text { Protein }(\mathrm{g})\end{array}$ & $\begin{array}{c}1.50 \\
358 \\
17 \cdot 0 \\
41.0 \\
8.0\end{array}$ & $\begin{array}{c}0.83 \\
199 \\
9 \cdot 0 \\
31.5 \\
5 \cdot 8\end{array}$ & $\begin{array}{l}1 \cdot 64 \\
393 \\
18 \cdot 5 \\
42 \cdot 2 \\
12 \cdot 2\end{array}$ & $\begin{array}{c}1 \cdot 26 \\
302 \\
14 \cdot 4 \\
36 \cdot 5 \\
11 \cdot 2\end{array}$ & $\begin{array}{l}-0.42 \\
-0.36 \\
-0.11 \\
-1.81\end{array}$ & $\begin{array}{l}\text { NS } \\
\text { NS } \\
\text { NS } \\
\text { NS }\end{array}$ \\
\hline $\begin{array}{l}\text { Total test daył } \\
\text { Energy: MJ } \\
\quad \text { kcal } \\
\text { Fat }(\mathrm{g}) \\
\mathrm{CHO}(\mathrm{g}) \\
\text { Protein }(\mathrm{g})\end{array}$ & $\begin{array}{c}8 \cdot 49 \\
2030 \\
79 \cdot 2 \\
274 \cdot 2 \\
66.9\end{array}$ & $\begin{array}{c}2 \cdot 24 \\
535 \\
22 \cdot 9 \\
88 \cdot 3 \\
16 \cdot 5\end{array}$ & $\begin{array}{c}9.47 \\
2266 \\
110 \cdot 3 \\
255 \cdot 6 \\
73.4\end{array}$ & $\begin{array}{c}2 \cdot 69 \\
643 \\
35 \cdot 2 \\
83 \cdot 7 \\
16 \cdot 9\end{array}$ & $\begin{array}{r}-1.70 \\
-4.06 \\
1.06 \\
-1.68\end{array}$ & $\begin{array}{r}0.01 \\
\text { NS } \\
\text { NS }\end{array}$ \\
\hline
\end{tabular}

* For details of subjects, procedures and test snacks, see pp. 522-525 and Table 2 respectively.

$\dagger$ Calculated from food items consumed from the snack box plus beverages consumed in the evening.

$\ddagger$ Calculated from the fixed breakfast, fixed lunch, ad libitum snack, ad libitum test dinner, snack box and beverages consumed throughout the day. 


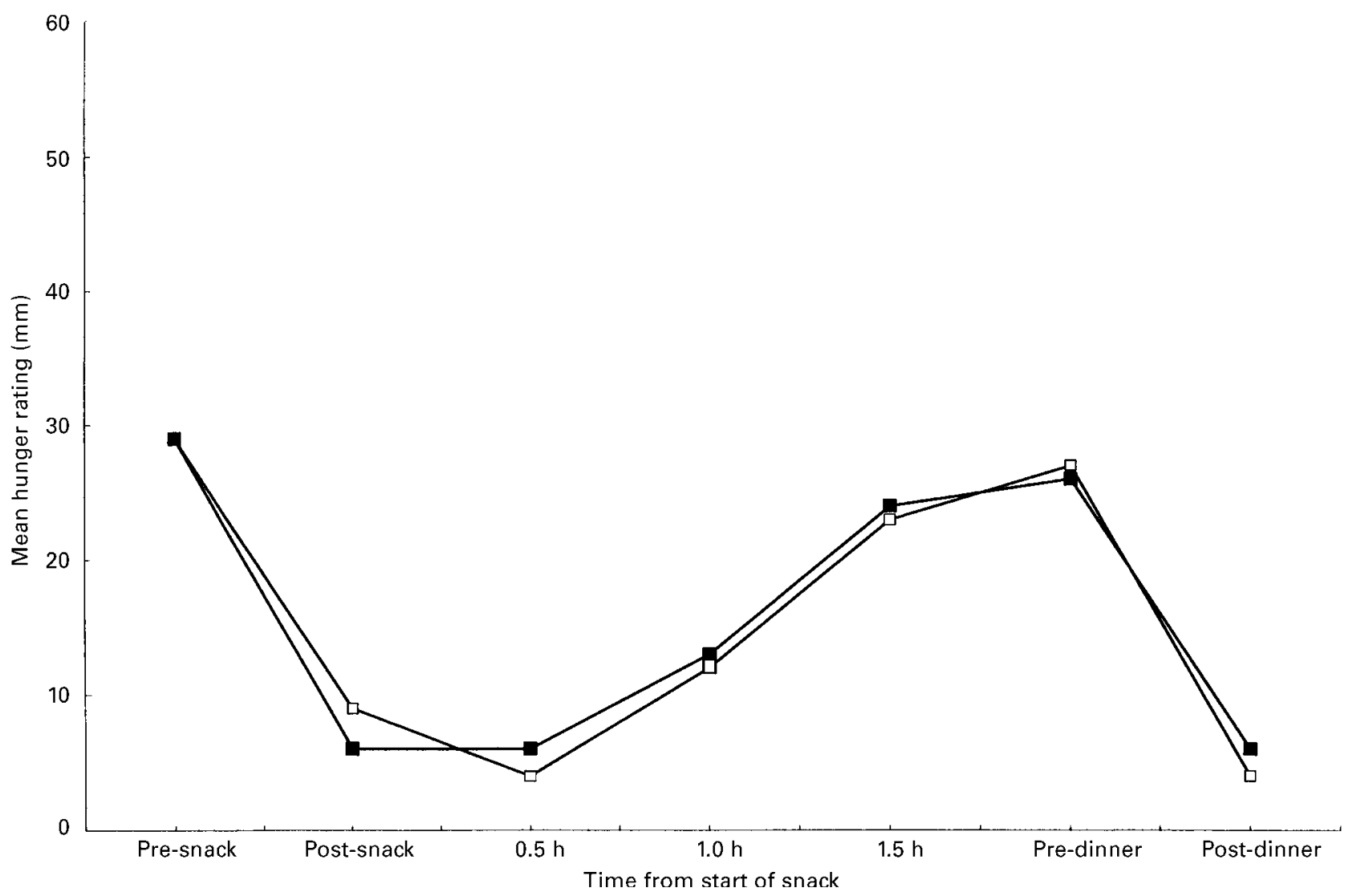

Fig. 2. Temporal profile of rated hunger immediately before (pre-snack) until immediately following ad libitum consumption of a high-fat ( $\square$ ) or high-carbohydrate $(\square)$ test snack in obese women. Subjective hunger ratings were measured on visual analogue scales with $100 \mathrm{~mm}$ lines anchored by descriptors at each end. For details of procedures and test snacks, see pp. 522-525 and Table 2.

hunger ratings from immediately before the start of the snack (pre-snack) to immediately following the test dinner. Hunger levels can be seen to fall after consumption of the snacks and then rise until the next meal. Hunger levels following the two snack types appear very similar. Twoway repeated measures ANOVA of hunger ratings from post-snack to pre-dinner showed a main effect of time $[F(4,48) 13.11, P<0.001]$, but no main effect of snack type $[F(1,12) 0 \cdot 00, \mathrm{NS}]$ or snack $\times$ time interaction effect $[F(4,48) 0 \cdot 19$, NS].

\section{Discussion}

Energy intake at a test meal was increased when high-fat foods were consumed freely relative to high-CHO foods. No intensification of satiety was observed with the high-fat foods as recorded hunger was similar following the high-fat and high-CHO test meals, even though they differed in energy value and weight. The palatability ratings of the high-fat and high-CHO test meals were similar. The highfat test meals, therefore, appear to have had a weaker effect on both satiation (meal size) and satiety (post-meal hunger).

Overeating at a meal with high-fat foods relative to high$\mathrm{CHO}$ foods has been demonstrated previously in normalweight men (Green et al. 1994; King \& Blundell, 1995) and obese women (Lawton et al. 1993), and appears to be a well-observed natural phenomenon (Blundell \& Macdiarmid, 1997). The results of the present study are in agreement with previous findings. The high-fat foods were more energy dense than the high-CHO foods. Stubbs et al. (1996) have demonstrated that when isoenergeticallydense high-fat and high-CHO foods are consumed ad libitum, energy intake of high-fat and high-CHO foods are similar. It is likely, therefore, that the weak effect of highfat foods on satiation is due to a high energy density. The consumption of high-fat foods at a test meal did not appear to increase satiety. Weight and volume are likely to influence satiation (Blundell \& Stubbs, 1998), particularly in short-term studies such as the present study.

Once ingested, the pre- and post-absorptive physiological responses of fat and $\mathrm{CHO}$ differ and the extent to which this difference influences satiety differentially should be considered (Blundell \& Stubbs, 1998). Blundell \& Stubbs (1999) have questioned whether the effect of energy density can be considered independently from the nutrients which provide the energy.

A compensatory reduction for the higher energy intake at the high-fat meal or snack was not seen in the subsequent test meal (dinner). Consequently, energy over the total test day was increased when the high-fat lunch was consumed. There appeared to be a trend towards a higher daily energy 
intake when the high-fat snack was consumed, although energy intake was not significantly increased following the high-fat snack (Table 4). A lack of compensatory reduction in energy intake of a subsequent meal following overconsumption of a high-fat meal (relative to high-CHO meal) has been demonstrated in lean men (Cotton et al. 1994). Correspondingly, consumption of a palatable ad libitum high-fat meal has been shown to lead to a higher daily energy intake than consumption of an equally palatable high-CHO snack in lean men (Green et al. 1994) and women (Green \& Blundell, 1996a). The present study demonstrates that obese women also show a similar response following overconsumption of high-fat foods at a meal. Energy intake at the subsequent meal was not reduced following a high-energy high-fat meal, resulting in an increase in overall daily energy intake. It is possible that a compensatory reduction in energy intake may have been delayed. Food intake may have been reduced in the days following the challenge to compensate for the increased intake with the high-fat foods. Other long-term studies on lean individuals, however, have suggested that energy compensation does not occur (Stubbs et al. 1995a,b).

An important consequence of the experimental food manipulations was the effect on mean daily fat intake, since high-fat diets have been associated with $\mathrm{CHD}$, various types of cancer and hyperlipidaemia, and may lead to complications in obese women. Ad libitum consumption of high-fat foods at both a snack and lunch meal resulted in an increase in the percentage energy obtained from fat in the diet over the total test day. Consumption of the high-CHO foods at a meal resulted in a lower percentage energy obtained from fat.

The lunch and snack test meals generated similar effects on satiation and satiety. The snack size was smaller than the lunch. The mean hunger level of the participants at the start of the snack test meal was lower than that at the start of the lunch meal. Food intake, therefore, may have been in response to hunger, although participants may have restricted their intake of the snack test meal and not the lunch due to cognitive factors. Women may perceive sweet snacks as unhealthy (Grogan et al. 1997).

Sweet high-fat snacks have been shown to lead to overconsumption in comparison with sweet high-CHO snacks in lean males (Green \& Blundell, 1996b). In the present study sweet high-fat snack food promoted overconsumption relative to sweet high-CHO snacks in obese females.

The participants' level of dietary restraint was not considered in the analyses of the study. It is unlikely that dietary restraint could explain the differences in consumption between the high-fat and the high-CHO foods. Only one participant was able to identify the food selections as being high-fat and high-CHO. The other participants reported that they were unaware of the macronutrient manipulations.

Previous studies on normal-weight individuals have shown that ad libitum consumption of high-fat foods results in increased energy intake but a reduction in the weight of food consumed (Blundell et al. 1995). However, it has been suggested that obese women eat the same weight of food whether it is high-fat or high-CHO (Lawton et al. 1993). The results of the present study indicate there was no significant effect of snack type on weight of the snack consumed. However, a greater weight of foods was consumed at the high-CHO test lunch than the high-fat test lunch. These experiments demonstrate that when presented with the opportunity to eat freely, individuals do not invariably eat a constant weight of food irrespective of the taste or composition. As in previous studies where foods varying in nutrient composition and energy density have been used, it is clear that palatability (Mela \& Rogers, 1998) and macronutrient content (Blundell et al. 1995) influence the amount (weight) of food eaten. Neither obese nor lean individuals automatically consume the same amount when foods are discernibly different. In the present study the obese participants did not show an internally consistent pattern; they ate significantly different weights at the lunch, and different weights (but not significant) at the snack.

These results demonstrate that the macronutrient content of food consumed at both a snack meal and main meal can affect satiation and satiety in healthy obese females. This effect has been demonstrated in previous studies with healthy lean men (Cotton et al. 1994; Green et al. 1994; King \& Blundell, 1995; Green \& Blundell, 1996b) and women (Green \& Blundell, 1996a) and one study with healthy obese women (Lawton et al. 1993). Ad libitum consumption of palatable high-fat foods relative to high$\mathrm{CHO}$ foods increased energy intake of a meal without intensifying satiety. Whilst consumption of high-fat foods resulted in a significant increase in daily energy intake only when the foods were consumed at lunch, energy intake from fat over the test day increased from $35 \%$ to $>40 \%$, regardless of whether high-fat foods were consumed at a snack or lunch meal.

\section{Acknowledgements}

We thank Mary O'Kane (Research Dietitian) for her assistance with recruiting participants, and the participants for taking part. This research was supported by a grant from the Institut de Recherches Internationales Servier.

\section{References}

Barkeling B, Rossner S \& Bjorvell S (1990) Effects of a high protein meal (meat) and a high-carbohydrate meal (vegetarian) on satiety measured by automated computerized monitoring of subsequent food intake, motivation to eat and food preferences. International Journal of Obesity 14, 743-751.

Blundell JE \& Burley VJ (1987) Satiation, satiety and the action of dietary fibre on food intake. International Journal of Obesity 11, Suppl. 1, 9-25.

Blundell JE, Burley VJ, Cotton JR \& Lawton CL (1993) Dietary fat and the control of energy intake: evaluating the effects of fat on meal size and postmeal satiety. American Journal of Clinical Nutrition 57, Suppl. 5, 772S-777S.

Blundell JE, Cotton JR, Delargy H, Green S, Greenough A, King NA \& Lawton CL (1995) The fat paradox: fat-induced satiety signals versus high fat overconsumption. International Journal of Obesity 19, 832-835.

Blundell JE \& Macdiarmid JI (1997) Passive overconsumption. 
Fat intake and short-term energy balance. Annals of the New York Academy of Sciences 827, 392-407.

Blundell JE \& Stubbs RJ (1998) Diet composition and the control of food intake in humans. In Handbook of Obesity, pp. 243-278 [GA Bray, C Bouchard and WPT James, editors]. New York: Marcel Dekker Inc.

Blundell JE \& Stubbs RJ (1999) High and low carbohydrate and fat intakes: limits imposed by appetite and palatability and their implications of energy balance. European Journal of Clinical Nutrition 52, 1-18.

Cotton JR, Burley VJ, Westrate JA \& Blundell JE (1994) Dietary fat and appetite: similarities and differences in the satiating effect of meals supplemented with either fat or carbohydrate. Journal of Human Nutrition and Dietetics 7, 11-24.

Drewnowski A (1990) Dietary fats: perceptions and preferences. Journal of American College of Nutrition 9, 431-435.

Drewnowski A, Kurth C, Holden-Wiltse J \& Saari J (1992) Food preferences in human obesity: carbohydrates versus fats. Appetite 18, 207-221.

Foltin RW, Fischman MW, Moran TH, Rolls BJ \& Kelly TH (1990) Caloric compensation for lunches varying in fat and carbohydrate content by humans in a residential laboratory. American Journal of Clinical Nutrition 52, 969-980.

Fricker J, Chapelot D, Pasquet P, Rozen R \& Apfelbaum M (1995) Effect of a covert fat dilution on the spontaneous food intake of lean and obese subjects. Appetite 24, 121-138.

Golay A \& Bobbioni E (1997) The role of dietary fat in obesity. International Journal of Obesity 21, Suppl. 3, S2-S11.

Green SM \& Blundell JE (1996a) Effect of fat- and sucrosecontaining foods on the size of eating episodes and energy intake in lean dietary restrained and unrestrained females: potential for causing overconsumption. European Journal of Clinical Nutrition 50, 625-635.

Green SM \& Blundell JE (1996b) Subjective and objective indices of the satiating effect of foods. Can people predict how filling a food will be? European Journal of Clinical Nutrition 50, 798-806.

Green SM \& Burley VJ (1995) The effects of snacking on energy intake and body weight. British Nutrition Foundation Nutrition Bulletin 78, 103-108.

Green SM, Burley VJ \& Blundell JE (1994) Effect of fat- and sucrose-containing foods on the size of eating episodes and energy intake in lean males: Potential for causing overconsumption. European Journal of Clinical Nutrition 48, 547-555.

Gregory J, Foster K, Tyler H \& Wiseman M (1990) The Dietary and Nutritional Survey of British Adults. London: H.M. Stationery Office.

Grogan SC, Bell R \& Connor M (1997) Eating sweet snacks: gender differences in attitudes and behaviour. Appetite 28, 1931 .

Heitmann BL, Lissner L, Sorensen TI \& Bengtsson C (1995) Dietary fat intake and weight gain in women genetically predisposed to obesity. American Journal of Clinical Nutrition 61, 1213-1217.

Holland B, Welch AA, Unwin ID, Buss DH, Paul AA \& Southgate DAT (1991) McCance and Widdowson's The Composition of Foods. 5th ed. London: Royal Society of Chemistry/Ministry of Agriculture, Fisheries and Food.

King NA \& Blundell JE (1995) High fat foods overcome the energy expenditure induced by high intensity cycling and running. European Journal of Clinical Nutrition 49, 114-123.
Lawton CL, Burley VJ, Wales JK \& Blundell JE (1993) Dietary fat and appetite control in obese subjects: weak effects on satiation and satiety. International Journal of Obesity 17, 409416.

Lawton CL, Delargy HJ, Smith FC, Hamilton V \& Blundell JE (1998) A medium-term intervention study on the impact of high- and low-fat snacks varying in sweetness and fat content: large shifts in daily fat intake but good compensation for daily energy intake. British Journal of Nutrition 80, 149-161.

Lissner L, Levitsky DA, Strupp BJ, Kalkwarf HJ \& Roe DA (1987) Dietary fat and the regulation of energy intake in human subjects. American Journal of Clinical Nutrition 46, 886-892.

Macdiarmid JI, Cade JE \& Blundell JE (1996) High and low fat consumers, their macronutrient intake and body mass index: further analysis of the National Diet and Nutrition Survey of British Adults. European Journal of Clinical Nutrition 50, 505512.

Macdiarmid JL, Vail A, Cade JE \& Blundell JE (1998) The sugarfat relationship revisited: differences in consumption between men and women of varying BMI. International Journal of Obesity 22, 1053-1061.

Mela DJ \& Rogers PJ (1993) 'Snack foods', overeating and obesity: relationships with food composition, palatability and eating behaviour. British Food Journal 95, 13-19.

Mela DJ \& Rogers PJ (1998) Food, Eating and Obesity. London: Chapman \& Hall.

Ministry of Agriculture Fisheries and Food (1993) Food Portion Sizes. 2nd ed. London: H.M. Stationery Office.

Prescott-Clarke P and Primatesta P, editors (1997) Health Survey for England 1995. A Survey Carried out on Behalf of the Department of Health, vol. 1. London: The Stationery Office.

Ranneries C, Bulow J, Buemann B, Christensen NJ, Madsen J \& Astrup A (1998) Fat metabolism in formerly obese women. American Journal of Physiology 274, E155-E161.

Rolls BJ, Kim-Harris S, Fischman MW, Foltin RW, Moran TH \& Stoner SA (1994) Satiety after preloads with different amounts of fat and carbohydrate: implications for obesity. American Journal of Clinical Nutrition 60, 476-487.

Spitzer L \& Rodin J (1981) Human eating behaviour: A critical review of studies in normal weight and overweight individuals. Appetite 2, 293-329.

Stubbs RJ, Goldberg GR, Murgatroyd PR \& Prentice AM (1993) Carbohydrate balance and day-to-day food intake in man. American Journal of Clinical Nutrition 57, 897-890.

Stubbs RJ, Harbron CG, Murgatroyd PR \& Prentice AM (1995a) Covert manipulation of dietary fat and energy density: effect on substrate flux and food intake in men eating ad libitum. American Journal of Clinical Nutrition 62, 316-329.

Stubbs RJ, Harbron CG \& Prentice AM (1996) Covert manipulation of the dietary fat to carbohydrate ratio of isoenergetically dense diets: effect on food intake in feeding men ad libitum. International Journal of Obesity 20, 651-660.

Stubbs RJ, Ritz P, Coward WA \& Prentice AM (1995b) Covert manipulation of the ratio of dietary fat to carbohydrate and energy density: effect on food intake and energy balance in free-living men eating ad libitum. American Journal of Clinical Nutrition 62, 330-337.

Warwick ZS \& Schiffman SS (1992) Role of dietary fat in calorie intake and weight gain. Neuroscience Biobehavioural Reviews 16, 585-596. 